\title{
Memoria, género y activismo. Resistencia a la dictadura y lucha por el aborto legal
}

\author{
Memory, gender and activism. Resistance to the dictatorship and struggle for \\ legal abortion right
}

Elizabeth Jelin

elijelin@gmail.com

CONICET/ Centro de Investigaciones Sociales.

Instituto de Desarrollo Económico y Social, Argentina

\section{Barbara Sutton}

bsutton@albany.edu

Departamento de Estudios de Mujeres, Género y

Sexualidad. Universidad de Albany, Estados Unidos

Cita sugerida: Jelin, E. y Sutton, B. (2021). Memoria, género y activismo. Resistencia a la dictadura y lucha por el aborto legal. Aletheia, 11(22), e099. https://doi.org/10.24215/18533701e099

\begin{abstract}
Resumen: El 26 de marzo de 2021 se realizó el panel virtual "Memoria, género y activismo. Resistencia a la dictadura y lucha por el aborto legal”. El evento fue organizado por Emilio Crenzel y Daniele Salerno en el marco del proyecto MEMORIGHTS - Memoria Cultural en el Activismo LGBT, con sede en la Universidad de Utrecht y en la Universidad de Buenos Aires, desarrollado dentro del programa Marie SklodowskaCurie de la Unión Europea. El panel contó también con la colaboración del proyecto del European Research Council "REACT - Remembering Activism" con sede en la Universidad de Utrecht (coordinadora Ann Rigney). Las participantes del panel fueron Elizabeth Jelin (CONICET - CIS-IDES) y Bárbara Sutton (SUNY - Albany) y estuvo coordinado por Emilio Crenzel (CONICET-UBA).
\end{abstract}

Palabras clave: Memoria, Género, Derechos Humanos.

\begin{abstract}
The panel "Memory, gender and activism. Resistance against dictatorship and struggle for legal abortion right" was held on March 26th, 2021. The event was organized by Emilio Crenzel and Daniele Salerno within the MEMORIGHTS project - Cultural Memory in LGBT Activism, based in Utrecht University and Buenos Aires University and developed by Marie Sklodowska-Curie program from the European Union. The panel had also the collaboration from the European Research Council "REACT- Remembering Activism", based in Utrecht University (Ann Rigney coordination). The lecturers of the panel were Elizabeth Jelin (CONICET - CIS-IDES) and Bárbara Sutton (SUNY - Albany) and was coordinated by Emilio Crenzel (CONICET-UBA).
\end{abstract}

Keywords: Memory, Gender, Human Rights.

\section{Emilio Crenzel:}

Bienvenidas todas y gracias por sumarse al encuentro. Podemos ver que la totalidad de asistentes al panel son mujeres. El gusto es compartido y la posibilidad de conversar con Bárbara Sutton y Elizabeth Jelin, quienes nos van a hablar de varios temas que vienen trabajando desde hace tanto tiempo, es muy importante. El panel va a comenzar con la intervención de Bárbara. 
Bárbara Sutton es profesora del Departamento de Estudios de Mujeres, Género y Sexualidad de la Universidad de Albany y es afiliada al Departamento de Sociología y Estudios en América Latina, el Caribe y los Latinos en Estados Unidos, de su Universidad. Es autora de Surviving State Terror: Women's Testimonies of Repression and Resistance in Argentina (2018) y Bodies in Crisis: Culture, Violence, and Women's Resistance in Neoliberal Argentina (2010).

\section{Bárbara Sutton:}

\section{Memoria, derechos humanos y activismo por el aborto legal en Argentina}

Muy buenos días. Es un gran honor para mí estar acá compartiendo este espacio con ustedes, y con Elizabeth Jelin en particular. Agradezco especialmente a Daniele Salerno y Emilio Crenzel por incluirme en este encuentro.

En esta presentación voy a explorar la interacción entre las memorias sobre violaciones a los derechos humanos perpetradas por la última dictadura (periodo 1976-1983) y las luchas contemporáneas por el derecho al aborto, en democracia.

En primer lugar y con respecto al aborto, recordemos que por casi un siglo el aborto voluntario en Argentina era ilegal, con ciertas excepciones a su punibilidad: los casos de violación o peligro para la vida o la salud. En el año 2018 se debatió la legalización del aborto en el Congreso de la Nación por primera vez, pero el proyecto fue rechazado en el Senado. En diciembre del 2020, el Congreso legalizó la interrupción voluntaria del embarazo hasta la semana 14 inclusive y el Presidente Alberto Fernández promulgó la ley en enero de este año.

Ahora vayamos más atrás en el tiempo. En cuanto a la última dictadura, como ya se conoce, ese régimen se destacó por la tortura masiva y la desaparición forzada de personas en centros clandestinos de detención. ¿Qué tiene esto que ver con el aborto?, se preguntarán. La respuesta corta es que el activismo por el derecho al aborto ha invocado - entre muchas otras cosas - el discurso de los derechos humanos y la memoria social asociada con el mismo como parte de su repertorio de denuncia acerca del daño causado por la ilegalidad y la clandestinidad del aborto. Además, sectores conservadores también han recurrido a esa historia, pero para bloquear la despenalización y la legalización del aborto.

Quienes estudian procesos de memoria colectiva han demostrado que las memorias no son estáticas, sino dinámicas y afectadas por las preocupaciones del presente. ${ }^{1}$ En este caso, estoy interesada por un lado en cómo la memoria del terrorismo de Estado ha moldeado aspectos del feminismo contemporáneo en Argentina - específicamente las luchas por el derecho al aborto - y por otro, cómo la movilización feminista actual influye en cómo se recuerda el pasado. Por ejemplo, cómo el feminismo ha ayudado a crear espacios para el reconocimiento y la reparación de las experiencias de mujeres que sufrieron violencias sexuales y generizadas, inclusive abortos forzados en detención clandestina.

Examinar estas dinámicas requiere recabar fuentes de datos dispares: fragmentos de información que se unen a manera de un collage quizás desordenado. Estas piezas se tocan en la intersección de distintas agendas de investigación que he desarrollado: Una línea centrada en memorias acerca de la dictadura y otra centrada en los movimientos feministas y de mujeres. En algún momento, estas agendas se comenzaron a superponer, tanto empírica como conceptualmente, uniendo temas de memoria colectiva y activismo por el derecho al aborto. 


\section{Cruces Empíricos}

Por un lado, en la investigación para mi libro Surviving State Terror (Sutton, 2018), que está basado en testimonios de mujeres sobrevivientes de los centros clandestinos de detención, me topé con narrativas sobre pérdidas de embarazo por las torturas o abortos inducidos en la clandestinidad. Por otro, y alrededor del mismo tiempo (año 2014), yo estaba haciendo también entrevistas para otro proyecto, focalizado en el activismo por el derecho al aborto. En el contexto de algunas de mis entrevistas con activistas, a veces me enteraba algo tangencialmente que la entrevistada había sido militante política en los 70s, exiliada o presa política de la dictadura.

Tampoco se me escapaba que el pañuelo verde que devino símbolo de la lucha por el derecho al aborto es también reminiscente del pañuelo blanco de las Madres de Plaza de Mayo, reconocidas por encabezar la lucha por los derechos humanos en Argentina. Y esa reminiscencia no es casual. Como me explicó una activista de la Campaña Nacional por el Derecho al Aborto Legal, Seguro y Gratuito, el pañuelo verde remite a una genealogía de lucha de las mujeres y por los derechos humanos en Argentina. En una entrevista realizada en el 2014, dijo: "Y el símbolo nuestro [... ] es un pañuelo verde, que es una ... especie de préstamo que hemos tomado de las Madres de Plaza de Mayo. Y ese símbolo ha tenido un enorme éxito en su identificación y adopción por toda clase de movimientos." A modo de ejemplo, podemos ver estas conexiones plasmadas en un dibujo de la ilustradora Mariana Baizán, que se hizo viral alrededor del primer debate por el derecho al aborto en el 2018. Vemos aquí la yuxtaposición de los dos pañuelos (el verde y el blanco), la unión de dos luchas, en este caso representada en clave intergeneracional.

\section{IMAGEN 1}

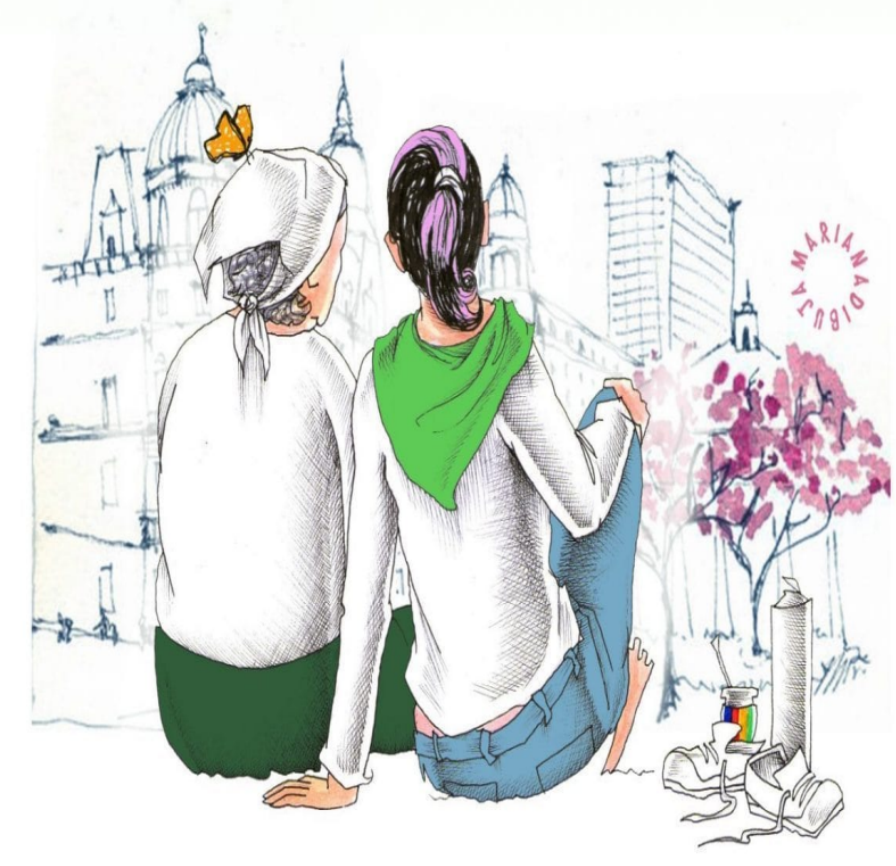

...AHORA... Y SIEMPRE...

\section{Mariana Dibuja/Página ${ }^{2}$}

Cuento todo esto un poco también para mostrar cómo fueron superponiéndose y convergiendo dos áreas de investigación separadas, y por lo tanto, generando las preguntas y temáticas que me interesa ahondar. 
De tal modo que comencé a examinar (o rever) varias fuentes de datos: testimonios de mujeres sobrevivientes de los centros clandestinos, ciertos discursos durante el debate parlamentario sobre la legalización del aborto en el 2018 (a lo cual podría agregar los del debate del 2020), decisiones judiciales recientes en juicios por crímenes de lesa humanidad con respecto a abortos forzados en el terrorismo de estado y entrevistas y documentos del activismo contemporáneos acerca del derecho al aborto en Argentina.

\section{Hilos Conceptuales}

Conceptualmente, este trabajo incluye diferentes hilos que se van entrelazando:

1. la noción de marcos de acción colectiva, en este caso aplicada al discurso de los derechos humanos (y su asociación con la democracia y la memoria social del terrorismo de Estado) en relación al aborto.

2. los sentidos y resonancias culturales de la noción de clandestinidad.

3. la aplicación del concepto de violencia de género/femicidio al daño por los abortos clandestinos.

4. el concepto jurídico de crimenes de lesa humanidad para abarcar los abortos forzados en el contexto de la represión estatal.

Veamos entonces cómo se conectan estos conceptos y fuentes de datos múltiples.

\section{Marcos de acción colectiva: Discurso de los derechos humanos}

Trabajos previos sobre el movimiento por el derecho al aborto en Argentina demuestran cómo la memoria de la dictadura y el discurso de los derechos humanos que se desarrolló como respuesta a atrocidades masivas se ha filtrado en la disputa sobre la legalización del aborto.

Por ejemplo, entre las activistas que apoyan este derecho hay quienes han criticado la postura de la Iglesia Católica acerca del aborto, trayendo a colación la actuación de la jerarquía de la Iglesia durante la dictadura. En el Encuentro Nacional de Mujeres de 1993 en Tucumán, en un taller autoconvocado sobre "Anticoncepción y aborto" las participantes observaron lo siguiente: "El doble discurso de la iglesia que dice defender la vida se olvida de la complicidad de la jerarquía eclesiástica cuando silenció durante la dictadura militar la tortura y muerte de mujeres embarazadas en cautiverio." ${ }^{3}$ Hay otros ejemplos de este tipo de observaciones en la historia del movimiento.

En cuanto al discurso de los derechos humanos, mi trabajo con Elizabeth Borland, y también con Nayla Vacarezza posteriormente, dan cuenta de cómo las activistas feministas han usado marcos de acción colectiva y símbolos asociados con el movimiento de derechos humanos y la democracia para apoyar el acceso al aborto y su legalización. ${ }^{4}$

El discurso de los derechos humanos ha estado asociado con la resistencia a la dictadura, pero también se fue expandiendo para abarcar una serie de derechos más amplios en el contexto democrático-entre ellos el derecho al aborto. Los derechos humanos fueron invocados en los fundamentos del proyecto de ley original de la Campaña, en varios otros argumentos y declaraciones y también en el artículo primero de la última versión de su proyecto, presentado en el 2019, que dice: "En ejercicio de sus derechos humanos, toda mujer u otras identidades con capacidad de gestar tienen derecho a decidir voluntariamente y acceder a la interrupción de su embarazo hasta las catorce semanas, inclusive, del proceso gestacional." ${ }^{5}$

Como sabemos, el discurso de los derechos humanos tiene carácter internacional y una temporalidad más larga, pero la potencia de su uso en el caso argentino puede también trazarse al legado del movimiento de derechos humanos y su resistencia a la dictadura.

Trabajos académicos también muestran que el campo progresista no es el único que despliega el lenguaje de los derechos humanos o que evoca de algún modo la memoria acerca de la dictadura. Por ejemplo, los 
grupos conservadores / religiosos que se oponen al derecho al aborto han recurrido a nociones de delitos de lesa humanidad y de genocidio para describir el aborto, haciendo referencia - y acá cito la investigación de Pablo Gudiño Bessone - "a los niños 'desaparecidos en democracia por aborto" (Gudiño Bessone, 2017: 103). Gudiño Bessone muestra cómo el mantra "Nunca más" - también título del informe de la Comisión Nacional sobre la Desaparición de Personas ${ }^{6}$ - se ha incorporado en las disputas en torno al aborto (Ibíd., 2012). Y esto no solo por las feministas sino por opositores conservadores que activan recuerdos del horror en un esfuerzo por avanzar sus causas.

Durante el debate en el Congreso sobre la legalización del aborto en el 2018, el Diputado José Fernando Orellana, quien se expresó en contra del aborto legal, hizo referencia a mujeres que habían sido detenidasdesaparecidas en la Escuela de Mecánica de la Armada (ESMA) donde funcionó un emblemático centro clandestino de detención durante la dictadura. Él dijo: "Yo acá veo muchos [...] pañuelos verdes, que hablaron de la ESMA. Si estas mujeres - a las que les rindo mi honor, mi homenaje - hubiesen abortado algunos que están sentados acá no hubiesen sido diputados. Y esas mujeres les dieron la vida." ${ }^{7}$ Esto tiene varias capas de significación, pero básicamente el Diputado Orellana se refería a legisladores/as cuyas madres fueron desaparecidas por la dictadura, dieron a luz en cautiverio y finalmente fueron asesinadas. Algo que omitió fue que estas mujeres embarazadas estaban a merced de represores que controlaban sus vidas y sus cuerpos. Estas mujeres no tenían poder de decidir en ningún sentido real; de hecho, muchas fueron asesinadas y sus hijas/hijos fueron apropiados como parte del plan sistemático de la dictadura. El Diputado Orellana también descuidó señalar los casos de mujeres embarazadas en cautiverio que perdieron sus embarazos debido a la tortura, o que fueron sometidas a procedimientos de abortos forzados en la clandestinidad.

\section{Clandestinidad}

Esto me lleva al segundo concepto, la clandestinidad, que nos ayuda a pensar sobre los vínculos entre la dictadura y la democracia en Argentina, y sobre cómo el doloroso legado del terror estatal ha influido en el activismo contemporáneo por el derecho al aborto. En trabajos anteriores, abordo lo que llamo "zonas de clandestinidad," yuxtaponiendo diferentes tipos de abortos clandestinos: casos de abortos forzados en los centros clandestinos de detención de la dictadura y los abortos clandestinos "normales" más generalizados - es decir, fuera de los centros clandestinos de detención, tanto en dictadura como en democracia (Sutton, 2017).

Los ecos culturales de estas diferentes formas de clandestinidad, que no son equivalentes, resuenan con connotaciones negativas: secreto, vulnerabilidad y la poderosa presencia de un estado cuyo brazo represivo daña a sus ciudadanos/as. En el caso de los centros clandestinos, las mujeres allí detenidas-desaparecidas sufrieron todo tipo de violencia sexual, y las mujeres embarazadas no se libraron de la tortura. Algunas de ellas fueron sometidas a abortos en condiciones marcadas por la extrema falta de libertad. En tiempos democráticos, en el contexto de una ley de aborto punitiva, las opciones de las mujeres con respecto a sus embarazos fueron tradicionalmente limitadas, y la mayoría de los abortos han sido en la clandestinidad, aunque con variadas condiciones de seguridad y cuidado. En algunos casos, la clandestinidad combinada con otras fuentes de vulnerabilidad, como recursos económicos escasos, llevaron no solo a situaciones humillantes, sino también a la muerte o a efectos negativos para la salud.

Gran parte del activismo por el derecho al aborto, entonces, ha tenido como objetivo sacar el aborto de la clandestinidad. Esta ha sido, por ejemplo, una estrategia de Socorristas en Red, una organización de activistas que acompañan a las personas que necesitan un aborto. En lugar de operar en completo secreto, han registrado sistemáticamente información sobre los abortos, publicándola y hablando abiertamente en un esfuerzo por “desclandestinizar." Una Socorrista a quien entrevisté en el 2019, explica: 
Para nosotras, justamente el mostrarnos públicamente es una manera de cuidarnos y de decir que claramente lo que hacemos es legítimo, dar información y recibirla es un derecho humano, y acompañar no es un delito, así que estamos acompañando a una persona ${ }^{8}$.

A través de sus intervenciones públicas, inclusive de manera vistosa, con sus pelucas rosa estridente, han ayudado a sacar al aborto de la clandestinidad.

Entre las iniciativas activistas en torno al histórico debate sobre la legalización del aborto en el 2018, se encontraba la Urna Verde. Esta iniciativa alentaba a las personas a compartir sus historias de aborto, escribiéndolas en boletas que luego se insertaban en una urna ubicada en el área de protesta al lado del Congreso. La idea era "liberar la clandestinidad a través de la palabra." Aquí la clandestinidad del aborto se contrapone a la democracia, representada simbólicamente a través de una urna. Lo que se nos recuerda implícitamente es que la clandestinidad no debería tener lugar en tiempos democráticos. Recordemos también que la clandestinidad es una condición muy connotada como negativa en la memoria social de la Argentina debido a las marcas de la dictadura.

Un volante del 2018 que explica el proyecto dice:

La urna, depositaria de nuestra historia colectiva de personas gestantes es símbolo de nuestro voto a quienes hoy tienen en sus manos la posibilidad de cambiar la historia, también es nuestra afirmación conjunta que a la clandestinidad no volvemos nunca más, que vivas nos queremos y que esperamos que lxs Senadorxs estén a la altura de nuestras demandas. ${ }^{10}$

Este pasaje es rico en significado y conexiones con varias luchas, ${ }^{11}$ pero centrémonos aquí en el "nunca más" volver a la clandestinidad. "Nunca más" evoca implícitamente el discurso asociado con la denuncia a los autoritarismos y nos recuerda la necesidad de repudiar las opresiones relacionadas con distintos tipos de clandestinidad.

\section{Violencia de género y femicidio}

Otra frase en el pasaje anteriormente citado - "vivas nos queremos" - se conecta con otro de los vínculos conceptuales que mencioné: la extensión del concepto de violencia de género. Este concepto se aplicó posteriormente en relación al aborto clandestino en la ilegalidad, y también sirve para hacer visibles las experiencias de mujeres en los centros clandestinos de detención.

Si bien la denuncia acerca de la violencia contra las mujeres / violencia de género / violencia sexual es de larga data en el movimiento feminista en Argentina, desde el 2015, una expresión de esta demanda es el movimiento Ni Una Menos, que atrajo a números masivos de mujeres a protestas callejeras. Uno de los hashtags / lemas difundidos a través del movimiento es \#VivasNosQueremos. A medida que se desarrolló la discusión en Ni Una Menos - y considerando las superposiciones con el movimiento por el derecho al aborto - se ha extendido la noción de violencia de género al daño producido por la clandestinidad de los abortos, señalando al Estado como responsable de la muerte de mujeres que perdieron la vida debido a abortos peligrosos en un contexto de criminalización. En una declaración de Ni Una Menos se afirma: "El aborto clandestino es femicidio en manos del Estado" y también, "no nos detenemos hasta que nuestra democracia contemple el derecho [al] aborto en condiciones dignas." 12 Por otro lado, dentro del movimiento por el derecho al aborto, también vemos cómo las activistas han integrado referencias a Ni Una Menos (así como referencias a prácticas democráticas como votar), por ejemplo, diciendo: "Ni una menos por aborto clandestino, yo voto por el Aborto Legal." 13

Tanto el movimiento por el derecho al aborto como Ni una Menos han producido eventos masivos, algunas de las manifestaciones más grandes de temática feminista en la historia argentina. Ahora, ¿cómo se conecta todo esto con la memoria del terrorismo de Estado? Antes hablé de cómo estas memorias influyeron en el activismo feminista contemporáneo, pero ahora me gustaría pasar a cómo el momento contemporáneo 
de efervescencia feminista ha provocado una nueva visita al pasado, en parte a través del foco en la violencia de género. Un ejemplo de esto es la exposición "Ser Mujeres en la ESMA" a través de la cual se revisó y reinterpretó el museo de la ESMA, donde funcionó el centro clandestino de detención. Lo hicieron destacando especialmente las experiencias de las mujeres en el terrorismo de estado, que incluyen delitos sexuales y también abortos forzados. Del siguiente modo se explica la exhibición:

En diálogo con las nuevas sensibilidades que despierta el movimiento de mujeres en el presente y sus demandas en la calle, la muestra vuelve a mirar el funcionamiento del centro clandestino de la ESMA a partir de la perspectiva de género, una dimensión hasta ahora ausente en la exhibición permanente del Museo. ${ }^{14}$

En la muestra se puede ver, por ejemplo, la intervención - al estilo de correcciones a mano en un texto impreso - en las descripciones de espacios del centro clandestino, como ser los baños. A través de estas correcciones se pone de relieve la presencia y experiencias específicas de las mujeres, tales como los abusos sexuales.

Alejandra Naftal, Directora del museo, explicó que esta es una respuesta a la "interpelación del presente hacia el pasado" ${ }^{15}$. Más precisamente, es también una interpelación del feminismo; y en las grabaciones de video y las imágenes de los eventos realizados en la muestra se pueden ver panelistas y visitantes al museo usando el pañuelo verde por el derecho al aborto. Durante mi propia visita al museo, pude ver en la exhibición algunas imágenes que conectan el pasado y el presente a través de la cobertura fotográfica del movimiento feminista y de mujeres (por integrantes de Pandilla Feminista), incluyendo activistas de la Campaña Nacional por el Derecho al Aborto Legal, Seguro y Gratuito.

\section{Lesa Humanidad}

Ahora abordaré brevemente el último hilo: crímenes de lesa humanidad. Si bien quienes se oponen al derecho al aborto han desplegado la noción de lesa humanidad para promover su causa, la escena en los tribunales reales es diferente. En los juicios en curso por ese tipo de delitos, se ha avanzado en incorporar una perspectiva de género y considerar la violencia sexual en su especificidad en lugar de simplemente subsumirla bajo la figura de los tormentos. ${ }^{16}$ Aquí también vemos una "interpelación del presente hacia el pasado," en el sentido de que los delitos de índole sexual podrían haber sido juzgados como tales en el Juicio a las Juntas en los 80s. Sin embargo, no lo fueron. En cambio, la atención que más tarde recibieron los delitos sexuales en las causas por crímenes de lesa humanidad está conectada a intervenciones a nivel nacional e internacional por parte de feministas, abogadas/os y otras/os profesionales con esa sensibilidad.

Podemos ver cómo los contextos contemporáneos, permeados por una mirada de género, afectan en el desarrollo de los mecanismos de la memoria colectiva y la justicia transicional. De tal modo que, en tiempos recientes, ha habido al menos dos casos con sentencias judiciales condenatorias que incluyen el aborto forzado en el contexto de la represión estatal como crímenes de lesa humanidad (CELS, 2021). Uno de los casos que atrajo la atención de los medios de comunicación masiva es el de Silvia Suppo, quien fue violada en cautiverio, quedó embarazada y luego fue sometida a un aborto "para reparar este error" — según le fue comunicado por uno de los represores a Suppo. ${ }^{17}$ Como sobreviviente, testificó en sede judicial en causas sobre delitos cometidos en el terrorismo de estado, pero tristemente fue asesinada tiempo después en el 2010. ${ }^{18}$ Sin embargo, un proceso judicial que juzgaba crímenes de lesa humanidad en que Suppo era damnificada continuó su curso, y en el 2018 los responsables fueron condenados, incluso en relación al aborto forzado. ${ }^{19}$

El yuxtaponer los abortos forzados en las detenciones clandestinas del terrorismo de estado y los abortos voluntarios en la clandestinidad "normal" por la ilegalidad del aborto, ya sea en dictadura o democracia, puede resultar discordante. Claramente no son situaciones equivalentes. Sin embargo, desde una perspectiva 
feminista, lo que se aspira es que ante cualquier situación de embarazo las mujeres puedan decidir libremente sobre sus cuerpos: ya sea para proseguir el embarazo, determinar las condiciones de nacimiento o decidir un aborto. Es significativo que en las fotos de militantes e integrantes de la familia de Silvia Suppo, se ve a su hija Marina Destéfani usando el pañuelo verde de la Campaña Nacional por el Derecho al Aborto Legal, Seguro, y Gratuito. Es decir, se puede deplorar el aborto en situaciones forzadas, y al mismo tiempo, defender el derecho de las mujeres y toda persona gestante a abortar si así lo deciden.

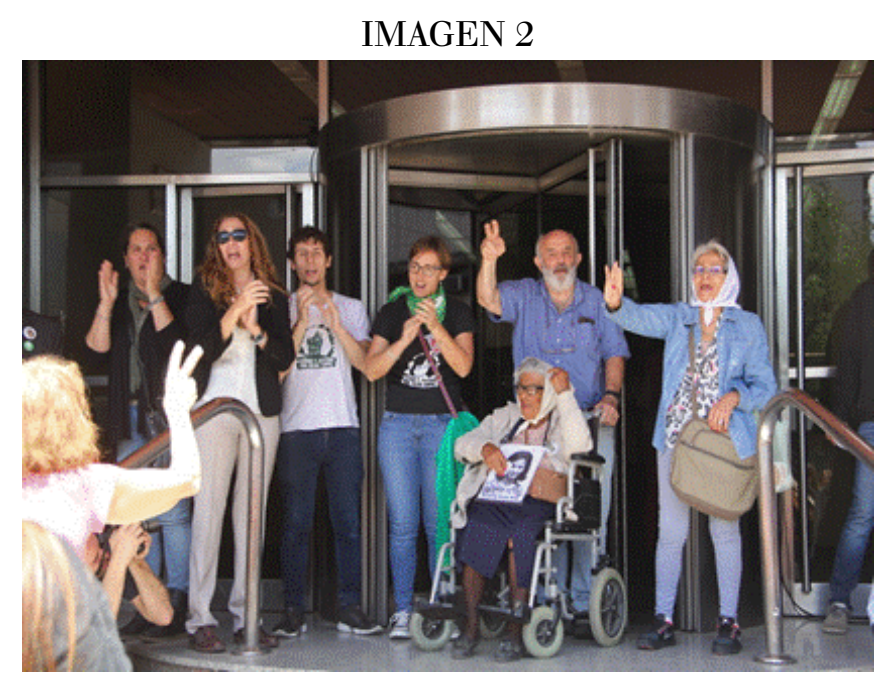

Fotos tomadas de la nota periodística Munné, G. (2018)

\section{A Modo de Conclusión}

Como he demostrado, estoy interesada en la memoria colectiva acerca del terrorismo de Estado y el movimiento de derechos humanos, sus efectos sobre el feminismo y el movimiento por el derecho al aborto, y cómo las intervenciones feministas del presente a su vez afectan el modo en que la memoria sobre violaciones a los derechos humanos es interpretada, resignificada y reparada.

Para quienes les interesen este tipo de cruces, recomiendo que consulten el archivo "Insumisas" en Memoria Abierta. ${ }^{20}$ Esta es una organización que fue muy importante en la investigación para mi libro Surviving State Terror - de hecho, en Memoria Abierta se produjeron los testimonios que analicé para ese proyecto. Hoy en día sigue recabando testimonios acerca del pasado que son esenciales para nuestro presente y futuro.

En esta presentación he intentado unir fragmentos del presente y del pasado, fragmentos conceptuales, fragmentos de datos. Los percibo a todos como parte de una pieza, de una historia que todavía se está escribiendo, y que se nutre de múltiples memorias e iniciativas de transformación social. Nos ayudan a transitar hacia distintos futuros posibles con un sentido de legado. Muchas Gracias.

Emilio: Muchísimas gracias, Bárbara, por tu presentación. Y ahora vamos a escuchar a Elizabeth Jelin, conocida por todos y todas como Shevy.

Shevy es investigadora superior del CONICET con sede en el CIS-IDES, y sus temas de investigación abarcan los derechos humanos, la ciudadanía, la familia, el género, las memorias de la represión y los movimientos sociales. Entre otras publicaciones, es autora de Las luchas sobre el pasado. Cómo construimos la memoria social, publicado por Siglo XXI en 2017, Los trabajos de la memoria, publicado por Siglo XXI España en 2003, y de un libro que acaba de salir, Cómo será el pasado, una conversación con Ricard Vinyes 
sobre el giro memorial. A fines de 2020, se publicó en la editorial de CLACSO la antología esencial de sus textos, La trama del texto.

Es un placer, Shevy, poder escucharte aquí.

\section{Elizabeth Jelin:}

Muchísimas gracias, Daniele y Emilio por esta invitación.

Emilio mencionó una serie de publicaciones, algunas de ellas muy recientes, como el libro con Ricard Vinyes, que todavía no llegó a la Argentina y será presentado el 15 de abril.

Para responder a la invitación que me propuso Danielle, es necesario volver a algunas ideas que ya planteé anteriormente, muchas de ellas ultra conocidas. En el mail de invitación, Daniele nos decía: "Nos gustaría que las intervenciones contribuyan a pensar cómo la memoria de la dictadura y de la transición a la democracia dialoga con las memorias de las militancias políticas que las precedieron; cómo se articulan o no las memorias de las acciones y del pensamiento de las y los militantes de los 60 y 70, víctimas del terrorismo de Estado, con las acciones y programas de los y las activistas de hoy; cómo se pueden incluir en el marco de la memoria de la posdictadura, las demandas y los relatos de grupos sociales y políticos cuya lucha podría no estar directamente anclada, o no limitarse, a la experiencia histórica de la última dictadura cívico militar."

Como ven, casi un programa de investigación. Sin duda, mi intervención se va a apoyar en lo que ya he hecho con el gran equipo de trabajo que integro. Creo que lo que Bárbara nos trajo hoy es una manera de encarar este tipo de cuestiones en un ámbito específico y que me parece sumamente importante. Son muchas las preguntas y líneas que surgen, y me volví un poco loca pensando qué puedo decir. Decidí que iba a comentar algunas observaciones organizadas en cuatro puntos.

Algunos de ellos, lo voy a hacer bastante rápido porque ya han sido escritos. En primer lugar, esta convocatoria tiene que ver con un activismo vinculado, por un lado, con la cuestión de género y las sexualidades y, por el otro, con las memorias. En este sentido, es importante comprender cómo la relación entre estas dos perspectivas (que Bárbara integró tan bien en lo que planteó), en realidad no se encuentra inscripta de antemano, ni debe ser así. Sino que esto ha sido una construcción desarrollada en el campo de las ciencias sociales de la región y ha sido, si se quiere, una especie de gran revolución. Porque la perspectiva de las ciencias sociales latinoamericanas ha sido históricamente más bien una perspectiva estructuralista, en la que se estudiaban las estructuras sociales. La realidad de los nuevos movimientos sociales de las décadas de los años 60 y 70 puso en jaque este enfoque. Había transformaciones en la sociedad que no podían ser entendidas desde perspectivas estructuralistas o institucionalistas de la época. Posteriormente, durante las décadas del 70 y del 80, la coyuntura política se vio atravesada por las preocupaciones en torno a la democracia y al surgimiento del paradigma de los derechos humanos.

Hago un pequeño punto y aparte aquí, para señalar que las luchas políticas en la región y en el mundo hasta mediados de los años 70 no eran leídas en clave de derechos humanos. Es a partir de los años 80, cuando en el mundo y, muy fuertemente en la región, empiezan a pensarse estos temas en clave de un paradigma de derechos humanos. Recordemos que la Declaración Universal de los Derechos Humanos era del año 1948, pero, hasta entonces los años 70 y 80, era un pedazo de papel. Fueron ciertos movimientos internacionales los que llevaron adelante esta nueva visión.

Lo que esto provocó fue, principalmente, la construcción de un paradigma centrado en la figura de la víctima, porque precisamente de eso se trata el paradigma de derechos humanos, de denunciar violaciones a los derechos básicos. No todas las desigualdades y no todas las injusticias fueron leídas en clave de derechos. Si bien hoy estamos acostumbrados/as a esta clave, -y Bárbara demostró muy bien cómo ahora la expresión derechos humanos aparece en muchos ámbitos- esto no necesariamente era así en aquellos momentos. Para el tema que nos convoca aquí, resulta importante destacar el trabajo de Diego Sempol que muestra cómo los movimientos gay lésbicos no necesariamente leyeron sus discriminaciones y desigualdades en la clave de 
derechos humanos. Hubo algunos que sí, otros que no y sobre ellos Sempol hace su análisis, específicamente, sobre la CHA en el caso de Argentina. Inclusive desde los feminismos, no todos los feminismos leyeron la discriminación de las mujeres y las desigualdades de género en clave de derechos humanos. Esto fue un proceso que se fue dando a lo largo del tiempo ${ }^{21}$.

Lo que me importa de esta convergencia entre memorias y género (o movimiento de mujeres, feminismos, o movimientos basados en la diversidad sexual), es que las ciencias sociales tuvieron que hacer un pequeño giro, un "pequeño gran giro", para incorporar estos procesos culturales y el análisis de las subjetividades, además de los procesos estructurales y los análisis institucionales. Y esto ocurrió al mismo tiempo en que se fueron desarrollando los estudios sobre memoria. En ese desarrollo, comenzó a haber una atención puesta en los procesos de memoria y en las luchas de las mujeres y las cuestiones de género. Quizás basada en mi propia biografía, juntar memoria y género parece algo casi natural. Pero esto no era así hace treinta años, no era así hace cuarenta años. No tenía nada que ver una cosa con la otra.

Este es un primer punto que quería marcar, porque a veces damos por supuesto cuestiones que tienen una historia, y esa historia no es, como dice el título de un importantísimo texto ${ }^{22}$, un matrimonio feliz desde el vamos. Hago referencia precisamente a los análisis que hablan del matrimonio mal avenido entre marxismo y feminismo, aquí aplicado a otro campo.

El segundo punto que quiero plantear se vincula con una visión sobre la historicidad de las memorias. Existen momentos históricos en los cuales se rescata, o está en el centro de la esfera pública, un determinado tema que involucra una manera de formular, un marco interpretativo sobre los acontecimientos, pero que posteriormente va a cambiar. Está claro que durante las dictaduras y en el momento inmediato posterior a las dictaduras la represión estatal y el terrorismo de Estado eran los temas centrales en la esfera pública. Y todas las memorias estaban centradas en esa represión estatal. De ahí también la centralidad del paradigma de los derechos humanos y la centralidad de las víctimas.

Si una va un poquito más atrás, hace dos años fue la conmemoración de los 50 años del 68, de los movimientos sociales del 68. Nos referimos a los movimientos en Francia, los del mayo francés, pero también de todos aquellos que ocurrieron en otras partes del mundo. Y con relación a América Latina, me interesa pensar en tres grandes acontecimientos que ocurrieron en los años 68 y 69. El primero de ellos refiere a los acontecimientos de Tlatelolco, en México, la enorme represión que ocurrió en México en el año 68. El otro fue en Brasil, en el movimiento estudiantil, en la Passeata dos cem mil. Y el tercero, el Cordobazo en la Argentina. Estos tres momentos constituyen tres ejemplos de movimientos sociales contestatarios en América latina, anclados en una visión de la unión obrero-estudiantil que ocurrieron en el mundo entero (el mayo francés también fue un acontecimiento obrero-estudiantil).

Como dicen los análisis del Mayo Francés, y Carlos Fuentes lo dijo en su momento, el Mayo Francés no podría haber existido si no hubiera existido en su momento la Revolución Cubana, Vietnam y muchas otras cosas que pasaron en otros lugares, y no necesariamente en el centro del mundo, o sea, en París.

Cuando miramos qué pasó con esos acontecimientos en América Latina, podemos ver que hubo una primera etapa en donde todas las memorias estuvieron centradas en la represión del Estado a esos movimientos sociales: cómo se destruyó al movimiento estudiantil en México, cómo se destruyó al movimiento estudiantil en Brasil. Llevó mucho tiempo, y esto es paralelo a lo que ocurrió en Argentina en la posdictadura, ir un pasito más atrás y mirar qué quería esa gente: mirar las ilusiones y los modelos sociales que esos movimientos estaban llevando adelante. Está claro que en el 68 la idea del Hombre Nuevo -y lo digo claramente, Hombre Nuevo- fue central. Pero, ¿en qué clave? En una clave, diríamos hoy en día, "machirula".

Y podemos mencionar una tercera etapa, (etapas que no necesariamente son etapas en el tiempo; algunas pueden coincidir, puede haber anticipaciones) en las cuales lo que se recupera es la memoria de las transformaciones sexo-genéricas que ocurrieron en el seno de esos movimientos. ¿Qué pasaba con las relaciones de género? Piensen ustedes que fue la época de la "píldora", de la liberación sexual, que fue la época en la que muchas mujeres tuvieron un protagonismo muy significativo. $\mathrm{Y}$ todo eso quedaba oculto en las 
memorias de la esfera pública. En definitiva, lleva mucho tiempo reconocer y desplegar en la esfera pública esas memorias que hacen mucho más a la vida cotidiana y a las relaciones humanas intersubjetivas. Hoy en día queda claro que se trató de un acontecimiento que también tuvo efectos profundos en esta dimensión de las relaciones humanas en la vida cotidiana.

Para hacer el paralelo con el caso argentino, podemos pensar que las memorias de las dictaduras tuvieron un primer momento de una fuerte centralidad de la represión política, que se tradujo en una atención a lo político en un sentido clásico, del sistema político. "Queremos democracia” y democracia quería decir "votar", "un parlamento", "un sistema de justicia que funcione”; en otras palabras, una institucionalidad democrática. Pero al mismo tiempo, podemos pensar que antes - en los años ' 60 y' 70 - había un fermento social, expresado en los movimientos sociales, que mantenía vinculaciones nada sencillas con los movimientos políticos. Los movimientos de mujeres, de pueblos originarios, de afrodescendientes, movimientos urbanos, movimientos de los sin tierra, que después quedaron aplacados durante las dictaduras, han vuelto a aparecer en esta etapa posterior.

En estos movimientos, aparecen también otras cuestiones. Bárbara hizo referencia al proyecto Insumisas de Memoria Abierta, que pone en relación y en tensión al movimiento de derechos humanos, con sus demandas muy centradas en las violaciones durante la dictadura (no en una noción amplia y universal de derechos humanos) y el movimiento de mujeres. Todo el trabajo del proyecto Insumisas es poner en vinculación un movimiento con el otro. Lo mismo se podría hacer con otros movimientos, por lo cual este es un modelo de trabajo especialmente significativo.

De esta manera resurgen los movimientos sociales en unas vinculaciones empíricamente diversas, (entre los reclamos vinculados con las dictaduras y las posdictaduras, y las demandas específicas de los movimientos sociales). Sin lugar a dudas, esto se puede ver en las marchas del 24 de marzo en la Argentina, pero también en las marchas del 11 de septiembre en Chile, y en las del 20 de mayo en Uruguay, donde numerosos grupos asisten con sus pancartas asociadas a los movimientos sin tierras, los movimientos urbanos, el movimiento piquetero (en el caso argentino). En definitiva, aparecen vinculaciones entre las demandas del movimiento de derechos humanos y la de estos otros movimientos diversos, con demandas específicas, que pueden ser encuadradas en demandas de derechos humanos. La diversidad de formas y la manera en que se fueron articulando es un objeto que tenemos que investigarlo mucho más. Lo que Bárbara nos trajo hoy es un excelente análisis de una de estas vinculaciones centrales para la Argentina, y no solo para la Argentina.

Desde estos otros movimientos, podemos mencionar otra etapa que se vincula con las demandas actuales respecto a las injusticias, vejaciones y situaciones estructurales de mucho más largo plazo. En el prólogo del informe de la Comisión de Verdad de Perú, se dice que no se puede afirmar que la violencia política en el Perú en el período 1980-2000 fue una violencia étnica, aunque sepamos que el 75\% de las víctimas eran quechua hablantes y que la proporción de víctimas del grupo Ashánica de la Amazonía fue increíblemente alta. Lo que se afirma en ese prólogo es que la violencia de ese período no podría haber ocurrido sin los siglos de discriminación estructural en el Perú.

Ahí hay un intento -inclusive desde lo institucional- de vincular lo que ocurre hoy con una situación anterior de larga data. En términos de estudios de memoria, tanto Silvia Rivera Cusicanqui como Ludmila Da Silva Catela hablan de "memorias largas" y de "memorias cortas". Al escucharla a Bárbara, ella decía "el ahora" con el Ni Una Menos y la ley de aborto, y "el antes” con la dictadura. Y lo que acá se está diciendo es "la dictadura y estos últimos cincuenta años" versus "quinientos años". De modo que estas memorias van mucho más atrás también: el corto y el largo plazo siempre son relativos, y, como tales, hay que comprenderlos desde una recuperación de demandas que tienen un anclaje estructural en nuestras sociedades, fuertemente atado a nuestra historia.

Barbara hizo mención a la muestra "Ser mujer en la ESMA". No fue fácil armarla. Estuve en la cocina de esa muestra que ahora es itinerante -tal como se puede ver en la página del museo del sitio, hay tres o cuatro circulando en distintos lugares del país. Existen también otros movimientos -y esto lo hablamos 
con Daniele- como el "30.400". Estos movimientos buscan visibilizar la realidad de ciertas víctimas en la dictadura, que responden a injusticias y discriminaciones específicas, las discriminaciones a las disidencias sexuales. Ese "30.400" es en realidad un movimiento que empezó y que tiene su eje central en Córdoba. Ellxs dicen " 30.000 ”, sí, pero además hay más de 400 personas que tienen sexualidades no son hegemónicas, y que fueron desaparecidas por su condición de sexualidad disidente. O sea, lo que hay es una diversificación de demandas de memoria de corto plazo, de la dictadura en adelante, que no son necesariamente las ancladas en los proyectos puramente políticos en sentido institucional, aunque sabemos que todo es político, y que lo personal es político.

Para terminar, ¿cuáles son los legados de todo esto? ¿qué quedó? Con relación al 68 hay un investigador alemán que en algún momento dijo que lo que quedó fue la revolución sexual. $\mathrm{O}$ sea, el gran movimiento político se deshizo, fue reprimido, no resurgió. Pero hubo una revolución sexual, un inicio de un cambio en las relaciones de género, y esto es algo que perdura. También las demandas sociales ligadas a identidades diferenciadas. Y aquí pongo juntas muchas identidades diferenciadas: los movimientos de los pueblos originarios, los afrodescendientes, los de diversidades sexuales, todos estos movimientos están teniendo un lugar en un espacio público ampliado. Y parecería que no están anclados a un proyecto político ligado al sistema político en un sentido estricto. No hay un partido político que los represente, sino que son transversales, y están anclados en estructuras de desigualdades muy profundas.

En verdad, estamos hablando de políticas o demandas que tienen que ver con el reconocimiento de la diversidad. Y la pregunta que queda abierta, y la pandemia no hace más que profundizarla, es ecómo se relacionan estas demandas de reconocimiento con los problemas de la desigualdad y la redistribución? Podemos tener un movimiento feminista que está reclamando muchas cosas, y al mismo tiempo tenemos una realidad cotidiana que está afectando de una manera insólita, imposible de imaginar hace muy poco, la situación de las mujeres en su vida cotidiana y las lógicas de cuidado, especialmente en comunidades donde las desigualdades sociales son muy profundas.

Termino con una anécdota personal. Hace dos días, el 24 de marzo, con mucha alegría, me llegó la comunicación de que tenía turno para vacunarme. En provincia, yo tengo una casa registrada en el municipio de Luján y me tocó. Y cuando estaba sentada a la espera, y después, cuando te explican cómo cuidarte, que te puede molestar donde te dieron la vacuna, que te tomes dos o tres días con calma, yo miraba a mi alrededor y éramos toda gente de 70 a 80 años, unas quince personas. Estaba sentada ahí y miraba, y me dije "qué privilegio el mío, que estoy aquí, de recibir esta vacuna frente a todo lo que está pasando en el mundo”, y por supuesto, más que nada centrada en imaginar lo que pasa en Brasil. Y lo que me pasó por la cabeza, la asociación de ideas que hice en ese momento, fue el título del libro de Primo Levi, "Los hundidos y los salvados" (1986). La vinculación entre lo que nos pasa cotidianamente en nuestro mundo y los grandes dramas que vivió la humanidad y los que seguiremos viviendo. Gracias.

Emilio: Bueno, muchísimas gracias Shevy por tu exposición.

Luego de las intervenciones, se abrió un interesante espacio para comentarios y consultas del público presente. Las preguntas y reflexiones compartidas pueden verse en el registro audiovisual del panel, a través del siguiente link:

Proyecto MEMORIGHTS [Memorigths] (26/03/2021) Memoria, género y activismo. Resistencia a la dictadura y lucha por el aborto legal [Archivo de video] Youtube. Recuperado de: https://www.youtube.co $\mathrm{m} /$ watch $\mathrm{v}=2 \mathrm{hmdeA} 3 \mathrm{a} 47 \mathrm{w} \& \mathrm{t}=213 \mathrm{~s}$ 


\section{REFERENCIAS}

Centro de Estudios Legales y Sociales CELS (2018) "Lesa humanidad: Condenaron a ex policías por el aborto forzado de Silvia Suppo". Octubre 8. URL: https://www.cels.org.ar/web/2018/10/lesa-humanidad-condenaron-a-ex-p olicias-por-el-aborto-forzado-de-silvia-suppo-el-embarazo-fue-por-una-violacion/

Gudiño Bessone, P. (2012). La disputa por la legalización del aborto en Argentina: Los usos políticos del Nunca Más, en Sociedad \& Equidad 4: 165-81.

Gudiño Bessone, P. (2017) "El aborto en el campo de la memoria y los derechos humanos. Feminismo, Iglesia católica y activismo pro-vida en Argentina”, en Aposta. Revista de Ciencias Sociales 73: 86-119.

Munné, G. (2018) Cuando el aborto es un crimen. El Cohete a la Luna. Recuperado de: https://www.elcohetealalu na.com/cuando-el-aborto-es-un-crimen/

Primo Levi (1986). Los hundidos y los salvados. Personalia de Muchnick Editores.

Sutton, B. (2017). Zonas de Clandestinidad y "Nuda Vida”: Mujeres, Cuerpo y Aborto, en Estudos Feministas 25(2): $889-902$.

Sutton, B. (2018). Surviving State Terror. Women's Testimonies of Repression and Resistance in Argentina. New York: New York University Press.

\section{Notas}

1 La extensa trayectoria de trabajo de mi co-panelista, Elizabeth Jelin, es iluminadora en ese sentido. Véase, por ejemplo: Jelin, E. (2014) Las múltiples temporalidades del testimonio: El pasado vivido y sus legados presentes. Clepsidra 1(1): 140-63; Jelin, E. (2017) La lucha por el pasado. Cómo construimos la memoria social. Buenos Aires: Siglo XXI Editores.

2 Imagen tomada de: PlanetaE [@mimundoenE]. (25/7/2019). Fragmento de la entrevista que hice a Mariana Baizán [Imagen adjunta] Facebook. Recuperado de: https://www.facebook.com/mimundoenE/photos/a.655868514597210 /1152481711602552/

3 Conclusiones del VIII Encuentro Nacional de Mujeres (1993) Taller Autoconvocado: Anticoncepción y Aborto, p. 62, Tucumán.

4 Véase Sutton, B. y Borland E. (2013) Framing Abortion Rights in Argentina's Encuentros Nacionales de Mujeres. Feminist Studies 39(1):194-234; Sutton, B. y Borland E. (2019) Abortion and Human Rights for Women in Argentina. Frontiers: Journal of Women Studies 40(2): 27-61; Sutton, B. y Vacarezza, N.L. (2020) Abortion Rights in Images: Visual Interventions by Activist Organizations in Argentina. Signs: Journal of Women in Culture and Society 45(3):73157. Sobre el concepto de "marcos de acción colectiva," véase Snow, D. A. y Benford, R.D. (1992) Master Frames and Cycles of Protest. Frontiers in Social Movement Theory, eds. A. D. Morris y C. McClurg Mueller. New Haven: Yale University Press.

5 Proyecto de Ley. Interrupción Voluntaria del Embarazo (20/3/2019) Campaña Nacional por el Derecho al Aborto Legal, Seguro y Gratuito . Recuperado de: http://www.abortolegal.com.ar/proyecto-de-ley-presentado-por-la-campan a/

6 Sobre la historia de este informe, véase Crenzel, E. (2008) La Historia Política del Nunca Más. La memoria de las desapariciones en la Argentina. Buenos Aires: Siglo XXI Editores.

7 Honorable Cámara de Diputados de la Nación (13/8/18). Diputado Orellana José Fernando - Sesión 13-06-2018 - PL. [Archivo de video] Recuperado de: https://www.youtube.com/watch?v=dp3Z82ySqrg

8 Entrevista a Socorrista en Red, 2019.

9 Urna Verde. (2018). Urna Verde en el Congreso: Yo Aborté (volante).

10 Urna Verde. (2018). Urna Verde en el Congreso: Yo Aborté (volante).

11 Además de la resonancia de la frase "nunca más" con el discurso de los derechos humanos, la referencia a "personas gestantes" refleja transformaciones en el activismo por el derecho al aborto orientadas a reconocer las contribuciones a la lucha de, y la relevancia de este derecho para, personas con diversas identidades sexuales y de género (más allá de las mujeres cis heterosexuales). Asimismo, y como veremos, "vivas nos queremos" se asocia con el movimiento Ni Una Menos, contra la violencia de género.

12 El Estado es responsable: el documento del \#NiUnaMenos. 6/3/17. Cosecha Roja. Recuperado de: http://cosecharoj a.org/estado-es-responsable/ 
$13 \mathrm{Ni}$ una menos por aborto clandestino, yo voto por el Aborto Legal. (28/9/18) Campaña Nacional por el Derecho al Aborto Legal, Seguro y Gratuito. Recuperado de: http://www.abortolegal.com.ar/comunicado-de-la-campana-nacional-por-el-derecho-al-aborto-legal-seguro-y-grat uito-28-de-septiembre-ni-una-menos-por-aborto-clandestino-yo-voto-por-el-aborto-legal/

14 Ser Mujeres en la ESMA. Testimonios para volver a mirar (14/3/2019) Museo Sitio de Memoria ESMA Recuperado de: http://www.museositioesma.gob.ar/item/ser-mujeres-en-la-esma/

15 Museo Sitio de Memoria ESMA (12/3/2019). Muestra Temporaria: 'Ser Mujeres en la ESMA.' (Archivo de video) Recuperado de: https://www.youtube.com/watch?v=5y5jrI52Hm4

16 De acuerdo a datos de la Procuradoría de Crímenes Contra la Humanidad, al 8 de marzo de 2021, "de un total de 1024 personas condenadas por crímenes de lesa humanidad [...], 121 fueron responsabilizadas por delitos sexuales y otras trece llegaron acusadas a debate y resultaron absueltas. Los condenados por estos crímenes, entonces, representan el $11 \%$ del total" (Ministerio Público Fiscal (8/03/2021) "Son 121 los condenados por violencia sexual en las sentencias por crímenes de lesa humanidad”. Recuperado de: https://www.fiscales.gob.ar/lesa-humanidad/son-121-los-condenados-p or-violencia-sexual-en-las-sentencias-por-crimenes-de-lesa-humanidad/).

17 Testimonio de Silvia Suppo, incorporado en el documental "Silvia”. Véase Kuschnir, Paula (22/07/2015) Silvia [Archivo de video] Recuperado de: https://www.youtube.com/watch?v=1h8wjUJyaN4

18 Respecto a este crimen: "La perseguida política Silvia Suppo fue apuñalada y asesinada en el centro de Rafaela el lunes 29 de marzo de 2010. Por esos hechos el Tribunal Oral de Santa Fe condenó a prisión perpetua a Rodrigo Sosa y Rodolfo Cóceres en abril del 2015. Una investigación fue iniciada para determinar la presunta vinculación del crimen con las causas de lesa humanidad en las cuales Suppo fue testigo y víctima". Ministerio Público Fiscal (29/12/2020) "El caso de Silvia Suppo. Casación Penal confirmó el fallo condenatorio contra ex policías por la violación y el aborto forzado de una perseguida política", s/n, Recuperado de: https://www.fiscales.gob.ar/lesa-humanidad/casacion-penal-confirmo-e 1-fallo-condenatorio-contra-ex-policias-por-la-violacion-y-el-aborto-forzado-de-una-perseguida-politica/

19 Esto fue ratificado por la Sala I de la Cámara Federal de Casación Penal (CFCP) en el 2020. Véase Ministerio Público Fiscal (29/12/2020) Ibidem, s/n.

20 \#Insumisas. Encuentros del feminismo y el movimiento de Derechos Humanos (9/12/2019) Memoria Abierta, s/n, Recuperado de: http://memoriaabierta.org.ar/wp/insumisas-encuentros-del-feminismo-y-el-movimiento-de-derechos -humanos/

21 Por este asunto puede verse Sempol, Diego (2013) De los baños a la calle: Historia del movimiento lésbico, gay, trans uruguayo (1984-2013), Montevideo, Ed. Sudamericana.

22 Hartmann, Heidi I (1979). The unhappy marriage of Marxism and feminism: towards a more progressive union, Capital \& Clas, 12 (2): 1-33. 